Original Research Paper

\title{
Chemical Mutagenesis for Improvement of Production of a Biologically Active Extracellular Polymeric Substance by Halomonas xianhensis SUR308
}

\author{
Jhuma Biswas and Amal K. Paul \\ Department of Botany, Microbiology Laboratory, University of Calcutta, Kolkata, India
}

\author{
Article history \\ Received: 29-06-2015 \\ Revised: 20-03-2016 \\ Accepted: 24-03-2016 \\ Corresponding Author: \\ Amal K. Paul \\ Department of Botany, \\ Microbiology Laboratory, \\ University of Calcutta, Kolkata, \\ India \\ Tel: 91-033-2461-5445; \\ 4959-5277-4711 \\ Fax: 0332461-4849 \\ Email:amalk_paul@yahoo.co.in
}

\begin{abstract}
A moderately halophilic bacterium, Halomonas xianhensis SUR308 (Genbank Accession No. KJ933394) isolated from solar saltern of Surala, Odisha, India was found to produce significant amount of a biologically active extracellular polymeric substances (EPS). Under optimized cultural conditions, the strain was able to produce $7.05 \mathrm{~g} \mathrm{~L}^{-1}$ of EPS after 8 days of incubation under shake culture. To enhance the EPS production efficiency, the isolate SUR308 was subjected to chemical mutagenesis following the use of hydroxylamine (HA), acridine orange (AO) and ethyl methanesulfonate (EMS). Evaluation of the toxicity of these mutagens indicated that EMS was comparatively toxic but effective for mutagenesis. Mutagenic treatments have resulted in the isolation of 58 amoxycillin resistant morphologically distinct phenotypes. Three of these mutant phenotypes (EM3, EM13 and HM6) were capable of producing 12.98, 11.97 and $11.21 \mathrm{~g} \mathrm{~L}^{-1}$ of EPS respectively in malt extract-yeast extract medium supplemented with casein hydrolysate with significant reduction of incubation period. Compared to wild type strain, mutant strains were found to produce 1.6-1.8 fold more EPS. However, the physico-chemical nature of the EPS derived from the mutants remained unaltered when compared with that of the wild type strain. These findings, therefore, have more impact on production economy of EPS for biotechnological applications.
\end{abstract}

Keywords: Halomomas xianhensis SUR308, Extracellular Polymeric Substances, Chemical Mutagenesis, Acridine Orange, Ethyl Methanesulfonate, Amoxycillin Resistance

\section{Introduction}

Halophilic bacteria belonging to the genus Halomonas have been identified as potential bioresources for the production of extracellular polymeric substances (EPS) (Llamas et al., 2012; Bouchotroch et al., 2001). The unusual physical and chemical properties (Margesin and Schinner, 2001) of the EPS derived from halophilic bacteria have drawn the attention of the microbial biotechnologists to explore the potentials of EPS production at commercially viable way. However, very few attempts have been made to enhance the EPS production by naturally occurring wild type halophilic strains. These involved improvement of bacterial strains by chemical or physical mutagenesis and selection of high yielding mutants by trial and error basis following laborious and time consuming steps (Sreeju et al., 2011; Iftikhar et al., 2010).

Several researchers (Fernandez-Castillo et al., 1990; Canovas et al., 1997; Fitt et al., 1989) have successfully induced mutations in a number of halophilic archaea (Haloferax, Haloarcula, Halococcus, and Halobacterium) as well as moderately halophilic bacteria (H. elongata and $H$. meridiana). They were able to obtain both auxotrophic and salt sensitive mutants by using hydroxylamine, ethyl methanesulfonate, N-methyl$\mathrm{N}$-nitro-N-nitrsoguanidine as mutagenic agents. Their experimental findings further established susceptibility and efficiency of mutagenesis in halophilic bacterial and archaeal strains. Llamas et al. (1999) on the contrary developed a successful method of chemical mutagenesis to obtain non-mucoid EPS deficient variants of EPS producing $H$. eurihalina . 
During the course of screening of halophilic microorganisms for the production of extracellular polymeric substances, we have reported the isolation of a moderately halophilic bacterium, Halomonas xianhensis SUR308 (Genbank Accession No. KJ933394) from a solar saltern of Surala, Odisha, India. So far there is no report on the production of EPS by Halomonas xianhensis. Production, purification and some biophysicochemical properties of EPS produced this isolate have been reported only recently by Biswas et al. (2015). The isolate SUR308 produced significant amount $(7.05 \mathrm{~g}$ $\mathrm{L}^{-1}$ ) of EPS when grown in malt extract-yeast extract (MY) medium supplemented with casein hydrolysate under batch culture. The EPS extracted from Halomonas xianhensis SUR308 possessed significant antioxidant activity with high emulsification capability. It did not show any cytotoxicity to human hepatocyte cell line. All these features may establish the potentiality of the EPS produced by $H$. xianhensis SUR308 towards industrial applications.

The objective of the present study was to develop high yielding mutant strains of the moderately halophilic bacterium, $H$. xianhensis SUR308 for effective production of EPS. Here, an attempt has been made to develop an efficient method of mutagenesis in $H$. xianhensis SUR308 by using a number of chemical mutagens such as hydroxylamine, ethyl methanesulfonate and acridine orange to obtain stable mutants with enhanced EPS production.

\section{Materials and Methods}

\section{Bacterial Strain and Cultural Conditions}

Halomonas xianhensis SUR308 (Genbank Accession No. KJ933394), a moderately halophilic EPS producing bacterium isolated from multi-pond solar salterns of Surala, Odisha, India reported from this laboratory was used throughout the present study of strain improvement by chemical mutagenesis and was maintained on agar slopes of MY medium (Quesada et al., 1993). For EPS production, MY medium supplemented with casein hydrolysate was used, which contained $\left(\mathrm{g} \mathrm{L}^{-1}\right)$ : $\mathrm{NaCl}, 25 ; \mathrm{MgCl}_{2}, 6 \mathrm{H}_{2} \mathrm{O}$, 9; $\mathrm{MgSO}_{4}, 7 \mathrm{H}_{2} \mathrm{O}, 13 ; \mathrm{CaCl}_{2}, 2 \mathrm{H}_{2} \mathrm{O}, 0.2 ; \mathrm{KCl}, 1.3$; $\mathrm{NaHCO}_{3}, 0.05 ; \mathrm{NaBr}, 0.15 ; \mathrm{FeCl}_{3}, 6 \mathrm{H}_{2} \mathrm{O}$, traces; glucose, 30; yeast extract, 3; malt extract, 3 and casein hydrolysate, 5 (pH 7.5).

\section{Chemicals}

Hydroxylamine, ethyl methanesulfonate, acridine orange, ciprofloxacin, chloramphenicol and amoxycillin were obtained from Himedia (India).

\section{Evaluation of Lethal Action of Chemical Mutagens}

The strain H. xianhensis SUR308 was grown in MY medium for $18 \mathrm{~h}$ at $32^{\circ} \mathrm{C}$ under continuous shaking $(120$ rpm). An aliquot $(1 \mathrm{~mL})$ of this culture was centrifuged $(5,000 \times \mathrm{g}$ for $5 \mathrm{~min})$ and the cell mass was washed twice with sterile $5 \% \mathrm{NaCl}$ solution. The washed cell mass was suspended in $5 \mathrm{~mL}$ of fresh MH medium (Ventosa et al., 1982) containing the desired amount of mutagens (hydroxylamine, acridine orange and ethyl methanesulfonate). The tubes were incubated at $32^{\circ} \mathrm{C}$ under continuous shaking $(120 \mathrm{rpm})$ and samples were withdrawn aseptically at regular intervals, harvested by centrifugation $(5,000 \times \mathrm{g}$, for $5 \mathrm{~min})$ and washed thrice with sterile saline. However, ethyl methanesulfonate treated cells were washed with $6 \%(\mathrm{w} / \mathrm{v})$ sodium thiosulfate. The treated cells were serially diluted and plated on $\mathrm{MH}$ agar medium and the plates were incubated at $32^{\circ} \mathrm{C}$ for $48 \mathrm{~h}$. The survivability was calculated as the ratio of viable count of the test sample per viable count of untreated control suspension.

\section{Mutagenesis and Isolation of Mutants}

Methods described elsewhere (Fernandez-Castillo et al., 1990; Nieto et al., 1992) was principally followed for inducing chemical mutagenesis of $H$. xianhensis SUR308. The mutagens, hydroxylamine, acridine orange and ethyl methanesulfonate were used at concentrations of $0.6-30,40-60$ and $20-60 \mu \mathrm{g} \mathrm{mL}^{-1}$ respectively so as to yield $1-10 \%$ viability, which is considered most suitable for mutagenesis in bacteria (Sweet and Moseley, 1976). To induce mutagenesis, cells were treated with the selected concentrations of mutagens for $30,60,90$ and $120 \mathrm{~min}$, harvested by centrifugation and washed with sterile saline. For EMS treated cells, 6\% sodium thiosulfate was used for washing the treated cells. Washed cells were transferred to fresh $\mathrm{MH}$ medium and grown for 3-6 days under continuous shaking (120 rpm). The culture was diluted serially and plated on MH agar medium supplemented with amoxycillin, chloramphenicol and ciprofloxacin $\left(30 \mu \mathrm{g} \mathrm{mL} L^{-1}\right)$. The plates were incubated at $32^{\circ} \mathrm{C}$ for 3-6 days.

The mutant colonies which appeared on antibiotic containing plates were picked up according to their morphological variation and maintained on slopes of the same medium supplemented with respective concentrations of the antibiotics. The mutants were repeatedly sub-cultured in the $\mathrm{MH}$ medium supplemented with antibiotics to confirm the stability of the mutants. The stable mutants were then preserved for further studies.

\section{Screening of Mutants for EPS Production}

The antibiotic resistant mutant clones were screened for their EPS production ability. Each of these mutants was grown in MY medium supplemented with 5\% $\mathrm{NaCl}$ and $1 \%$ glucose under continuous shaking (120 $\mathrm{rpm}$ ) at $32^{\circ} \mathrm{C}$ for 4 days and the soluble EPS of the supernatant was precipitated with double volumes of 
chilled ethanol. The EPS was collected by centrifugation $(12,000 \times \mathrm{g}, 10 \mathrm{~min})$, dissolved in deionized water and quantified in terms of its carbohydrate content $\left(\mathrm{g} \mathrm{L}^{-1}\right)$ by using Dubois method (Dubois et al., 1956).

\section{Time Course of Growth and EPS Production by Mutant Strains}

Time course of growth and EPS production by the selected antibiotic resistant mutants were determined in MY medium supplemented with casein hydrolysate and $3 \%(\mathrm{w} / \mathrm{v})$ glucose for 12 days under continuous shaking $(120 \mathrm{rpm})$ and aliquots were withdrawn from the growing cultures at an interval of 2 days. Growth of the culture was determined by measuring the optical density at $540 \mathrm{~nm}$ and EPS production was quantified in terms of its carbohydrate $\left(\mathrm{g} \mathrm{L}^{-1}\right)$ content as measured by the Dubois method (Dubois et al., 1956).

\section{Isolation and Purification of the EPS}

To extract the soluble EPS, the cultures after the desired period of incubation were centrifuged at $12,000 \times \mathrm{g}$ for $30 \mathrm{~min}$ and the EPS was precipitated with double volumes of chilled absolute ethanol and incubated overnight at $4^{\circ} \mathrm{C}$. The precipitate was then collected by centrifugation. Cell bound EPS was extracted from the cell mass following washing with hot saline water, centrifuged at $12,000 \times \mathrm{g}$ for $15 \mathrm{~min}$ and precipitated with chilled ethanol as usual.

Both soluble and cell bound EPS were pooled, washed with $70 \%$ chilled ethanol, dissolved in distilled water and dialyzed against distilled water at $4{ }^{\circ} \mathrm{C}$. The dialyzed EPS was further precipitated with chilled ethanol, dissolved in distilled water and lyophilized at $56^{\circ} \mathrm{C}$ in a lyophilizer (LSL-Secfroid).

\section{Phenotypic Characterization of the Potent Mutants}

The selected amoxycillin resistant mutants were characterized physio-biochemically by using standard microbiological methods as described by Gerhardt et al. (1994). The antibiotic sensitivity of the mutants was determined by disc-diffusion method. Antibiotic containing discs (6 $\mathrm{mm}$ dia, Himedia) were placed on MY agar plates seeded with the mutant strains and incubated at $32^{\circ} \mathrm{C}$ for $24 \mathrm{~h}$. The diameter of inhibition zones were measured to nearest $\mathrm{mm}$ and categorized as sensitive, intermediate and resistant.

To check the sugar utilization pattern, the isolates were grown on basal MH medium supplemented with $1 \%(\mathrm{w} / \mathrm{v})$ sugar and incubated at $32^{\circ} \mathrm{C}$ for $24 \mathrm{~h}$ and compared with the growth observed on control plate (with no carbon source). For acid production phenol red medium supplemented with $1 \%$ sugar was used and changes of color from red to yellow indicated acid production.
Tolerance of $\mathrm{NaCl}$ by the selected mutants was tested on basal $\mathrm{MH}$ agar medium supplemented with different concentrations of $\mathrm{NaCl}(0-25 \%$, w/v). The plate inoculated with the strains was incubated at $32^{\circ} \mathrm{C}$ for 2 days and growth was measured visually. Heavy metal tolerance of the mutant strains were compared with that of the wild type on basal MH agar supplemented with metals of different concentrations. The lowest concentration of metal that completely inhibited the growth of the bacterial strains was considered as Minimal Inhibitory Concentration (MIC). Plates were inoculated with a loopful of mutant bacterial strains from growing cultures. Controls were maintained consisting of medium without metals and inoculated with microorganisms. The plates were incubated at $32^{\circ} \mathrm{C}$ for $3-5$ days.

\section{FTIR and EDX Analysis of the Purified EPS}

For FTIR analysis, the purified EPS samples in $\mathrm{KBr}$ pellets were scanned in the region of $4000-400 \mathrm{~cm}^{-1}$ on a GX FTIR system (Jasco 6300, USA), while elemental analysis of EPS was done using energy dispersive X-ray spectroscopy (SEM, JEOL).

\section{Results}

\section{Lethality of Chemical Mutagens}

Toxicity of chemical mutagens such as hydroxylamine (HA), acridine orange (AO) and ethyl methanesulfonate (EMS) at different concentrations against $H$. xianhensis SUR308 cells was determined as a function of time and is presented in Fig. 1a-c. The survivability of SUR308 cells was found to decrease with increase in concentrations of mutagens as well as time of exposure. Lethality studies further demonstrated the existence of shoulder in survival curves followed by an exponential loss of viability for each of the mutagens.

Hydroxylamine at concentrations higher than $0.6 \mathrm{mg}$ $\mathrm{mL}^{-1}$ with a time exposure for more than $30 \mathrm{~min}$ showed a remarkable decrease in survivality $(0.13-0.0001 \%)$ of cells, while the lower concentration $\left(0.6 \mathrm{mg} \mathrm{mL}^{-1}\right)$ appeared to be nontoxic to $H$. xianhensis cells even after an exposure of $120 \mathrm{~min}$ (Fig. 1a).

When the cells were treated with acridine orange (AO), the survivality was not severely affected until the concentrations reached to $60-80 \mu \mathrm{g} \mathrm{mL} \mathrm{mL}^{-1}$ with an exposure for 90-120 min. Furthermore, cells exposed to $10 \mu \mathrm{g} \mathrm{mL}^{-1}$ of AO for 30-120 min showed very high survivality (Fig. 1b).

Ethyl methanesulfonate (EMS) was more lethal than acridine orange as the survivality was decreased remarkably $(0.48-0.00001 \%)$ when the cells were treated with $60-80 \mu \mathrm{g} \mathrm{mL}^{-1}$ of EMS for 90-120 min. Strikingly, EMS at $10 \mu \mathrm{g} \mathrm{mL}^{-1}$ was not inhibitory to SUR308 cells even up to $120 \mathrm{~min}$ of exposure (Fig. 1c). 


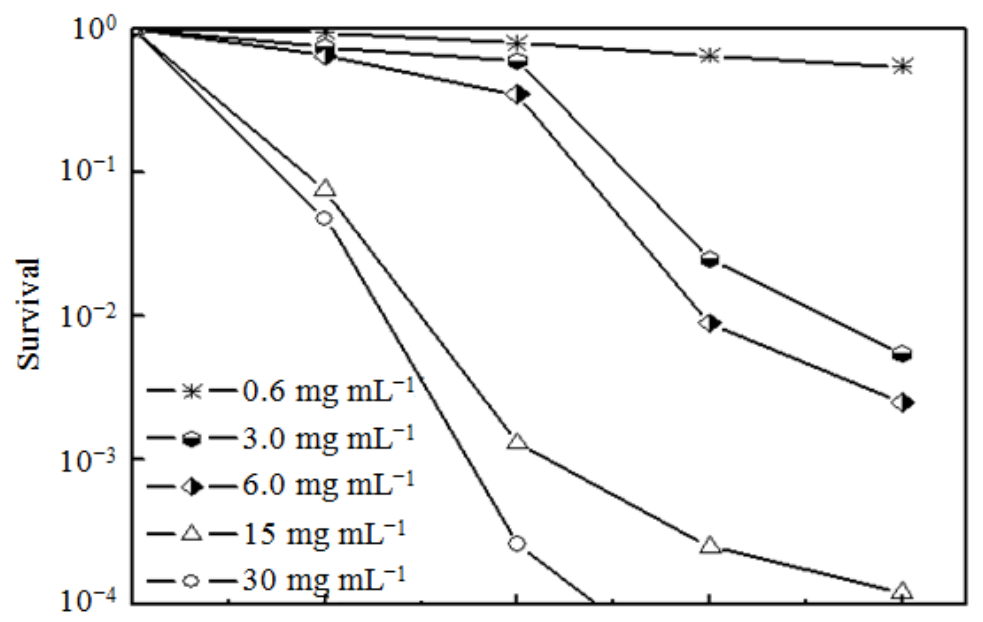

(a)

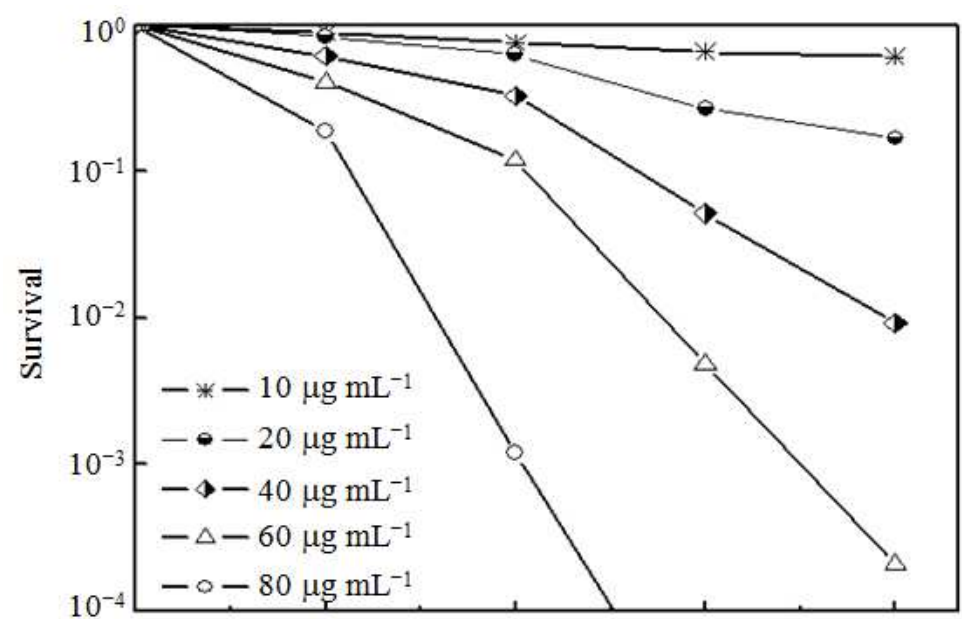

(b)

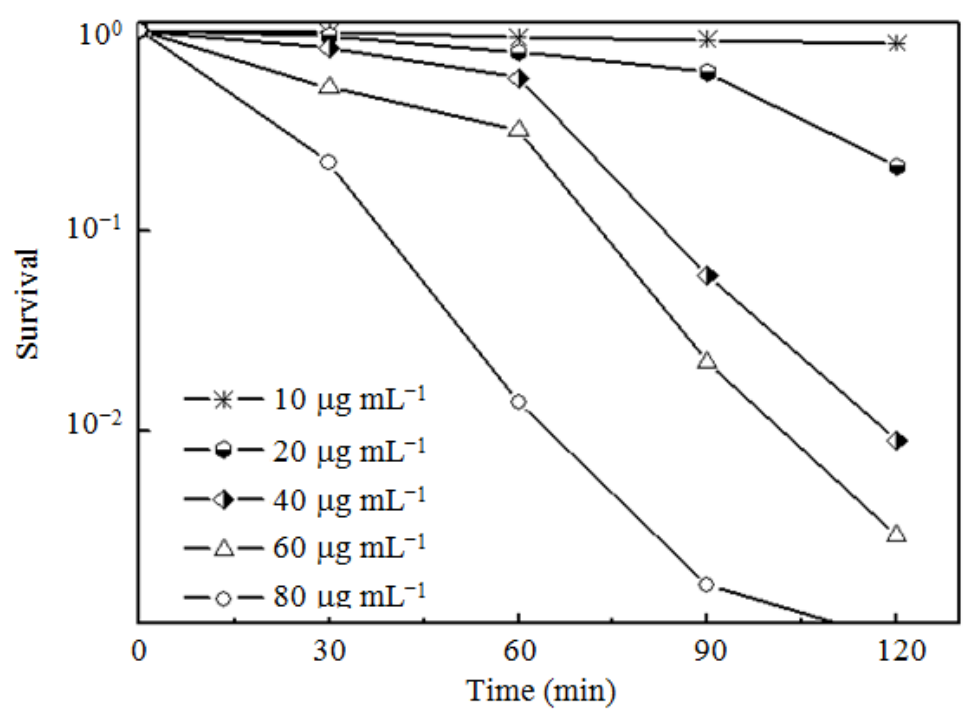

(c)

Fig. 1. Effect of hydroxylamine (a), acridine orange (b) and ethyl methanesulfonate (c) on the viability of H. xianhensis SUR308 cells as a function of concentration and duration of exposure 


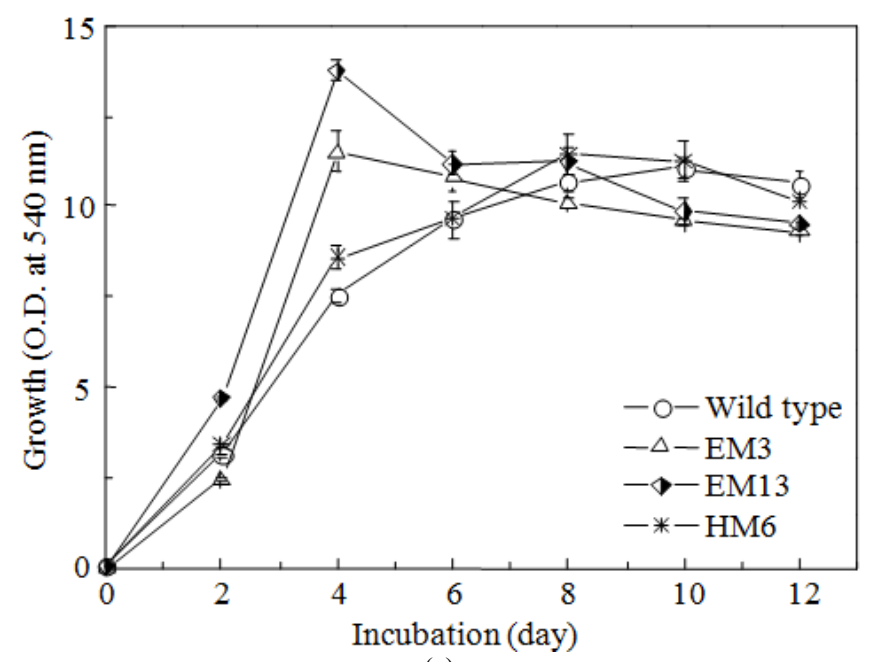

(a)

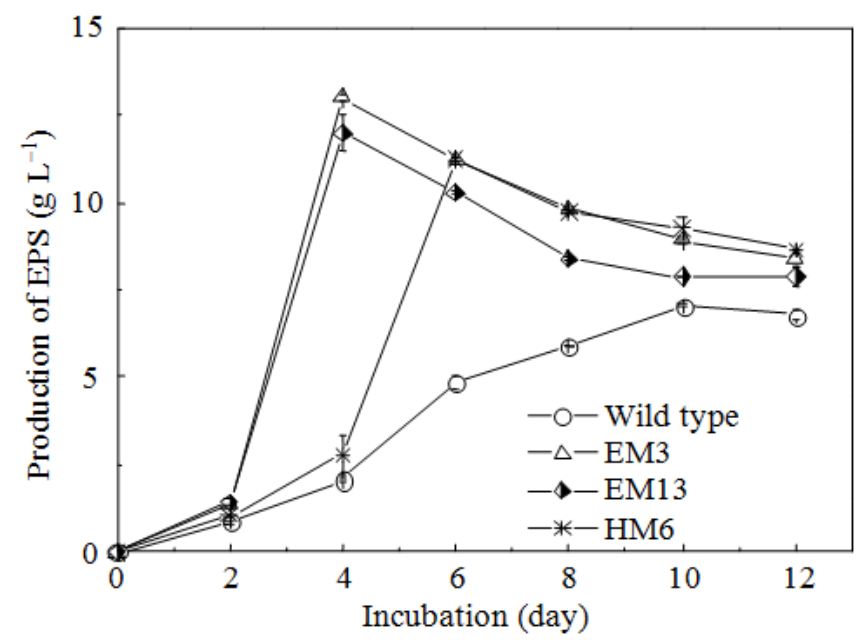

(b)

Fig. 2. Time course of growth (a) and EPS production (b) by the wildtype strain and selected amoxycillin-resistant mutants of $H$. xianhensis SUR308

\section{Isolation of Mutants and Screening for EPS Production}

Cells treated with suitable concentrations of mutagens were grown in fresh $\mathrm{MH}$ medium and plated on $\mathrm{MH}$ agar medium supplemented with amoxycillin, ciprofloxacin and chloramphenicol $\left(30 \mu \mathrm{g} \mathrm{mL}^{-1}\right)$. A total of 58 morphologically distinct amoxycillin resistant mutant clones were obtained. Among these, 41 were obtained from EMS treated cells and 16 from HA treated cells, while from acridine orange treated cells only one mutant cell type was obtained (Table 1). When the mutants were screened for EPS production in MY medium supplemented with $5 \%(\mathrm{w} / \mathrm{v}) \mathrm{NaCl}$ and $1 \%$ $(\mathrm{w} / \mathrm{v})$ glucose, it was observed that out of these 58 mutants, 18 produced $0.5-3 \mathrm{~g} \mathrm{~L}^{-1}$ of EPS, 37 produced $3.1-6 \mathrm{~g} \mathrm{~L}^{-1}$ of EPS and only 3 (EM3, EM13 and HM6) produced EPS more than $6 \mathrm{~g} \mathrm{~L}^{-1}$. These three mutant strains were selected for further studies.

\section{Time Course of Growth and EPS Production by Selected Mutants}

The selected amoxycillin resistant mutants (EM3, EM13 and HM6) were grown in MY medium supplemented with casein hydrolysate at $32^{\circ} \mathrm{C}$ for 12 days under continuous shaking (120 rpm). Time course of growth and EPS production (Fig. 2a and $2 b$ ) revealed that the mutants, EM3, EM13 and HM6 produced 12.98, 11.97 and $11.21 \mathrm{~g} \mathrm{~L}^{-1}$ of EPS respectively after 4, 4 and 6 days of incubation, while the wild type strain (SUR308) produced only $7.05 \mathrm{~g} \mathrm{~L}^{-1}$ of EPS after 8 days.

\section{Phenotypic Characterization of Selected Mutants}

Colonies of the selected mutants as appeared on $\mathrm{MH}$ agar showed distinct morphological variation with wild type strain (Fig. 3). While cells of wild type strain remain single in culture, mutant cells become elongated and aggregated during the production of EPS (Fig. 4). 


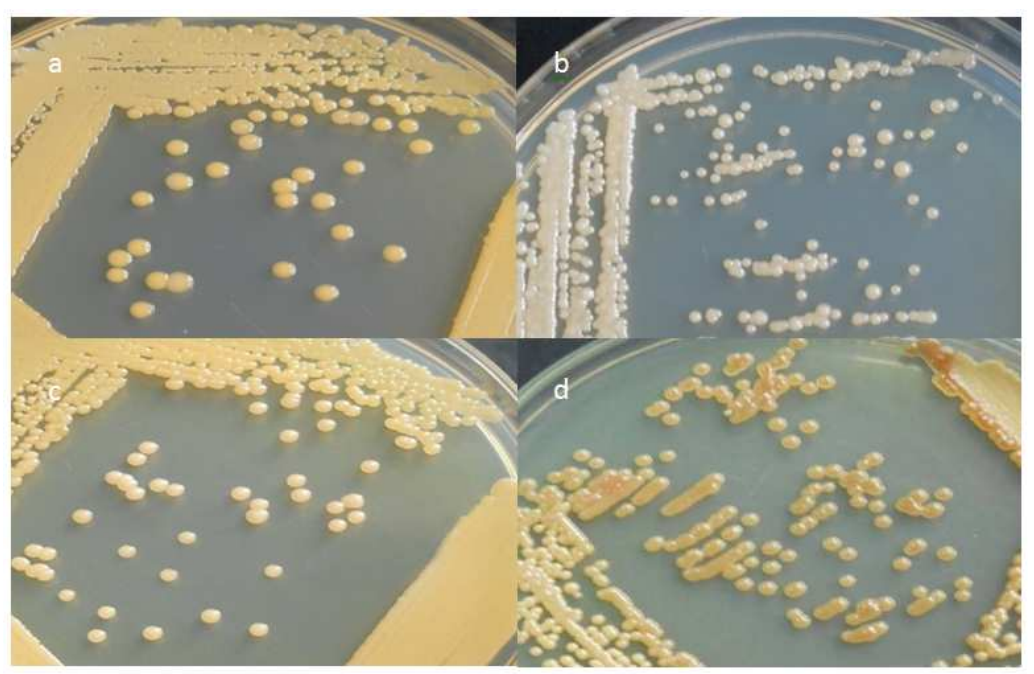

Fig. 3. Colony morphology of the wild type strain (a) and selected amoxycillin-resistant mutants [EM3 (b), EM13 (c), HM6 (d)] of H. xianhensis SUR308

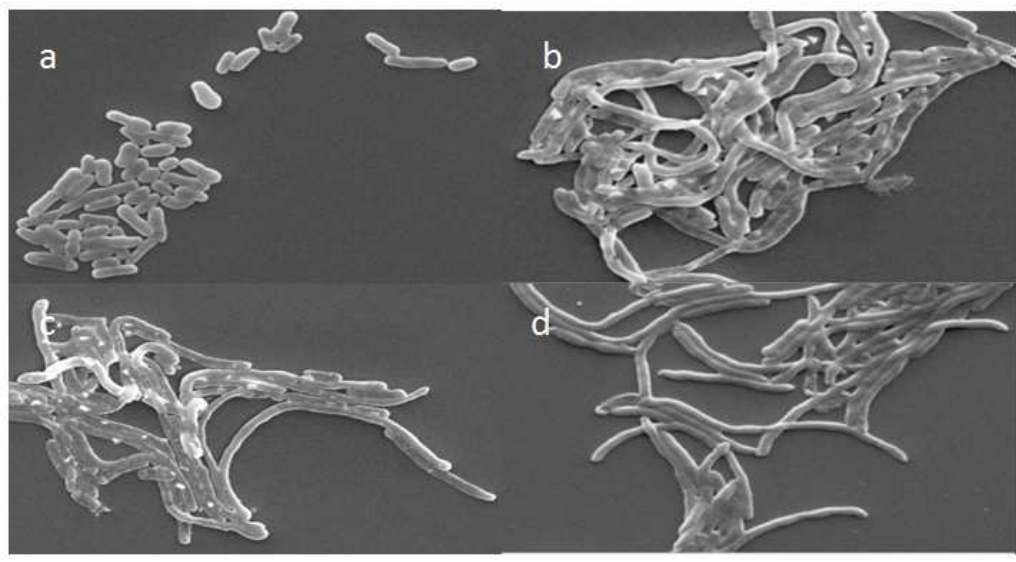

Fig. 4. Cell morphology of the wild type strain (a) and selected amoxycillin-resistant mutants [EM3 (b), EM13 (c), HM6 (d)] of $H$. xianhensis SUR308

Among the mutant strains, EM3 showed high degree of antibiotic resistance (ARI $=0.42)$, while EM13 turned out as the most sensitive one compared to the wild type strain (Table 2). The antibiotic resistance profile of the wild type and the mutants revealed an interchange of resistance and sensitivity towards amoxycillin $(30 \mu \mathrm{g})$, kanamycin $(30 \mu \mathrm{g})$, methicillin $(5 \mu \mathrm{g})$, neomycin (30 $\mu \mathrm{g})$, netillin $(10 \mu \mathrm{g})$ and streptomycin $(10 \mu \mathrm{g})$ (Table 2). Moreover, utilization and fermentation pattern of twenty different sugars so far tested revealed (Fig. 5) that the mutant strain EM3 has become more efficient in utilizing as well as fermenting the tested sugars compared to the wild type strain.

All the amoxycillin-resistant mutants showed more or less identical level of tolerance towards $\mathrm{Co}, \mathrm{Mn}$ and $\mathrm{Hg}$. In general, the mutant strains showed greater sensitivity towards $\mathrm{Cr}, \mathrm{Zn}$ and $\mathrm{Pb}$ but two of them (EM13 and
HM6) appeared to have acquired greater resistance to Ag compared to wild type (Table 3). None of the mutants, however, were able to grow in media contain $>5 \% \mathrm{NaCl}$ (results not shown).

\section{Physico-Chemical Properties of EPS Derived from the Mutants}

EPS produced by the selected amoxycillin resistant mutant strains under optimized cultural conditions were isolated and purified following the methods of precipitation, washing and dialysis against deionized water, and freeze drying. The overlaid FTIR spectra of the purified EPS produced by the amoxycillin resistant mutant strains and the wild type SUR308 clearly showed similar characteristic functional groups such as broad stretching hydroxyl group at $3409 \mathrm{~cm}^{-1}$ and a weak C-H stretching peak of methyl group at $2929 \mathrm{~cm}^{-1}$. 


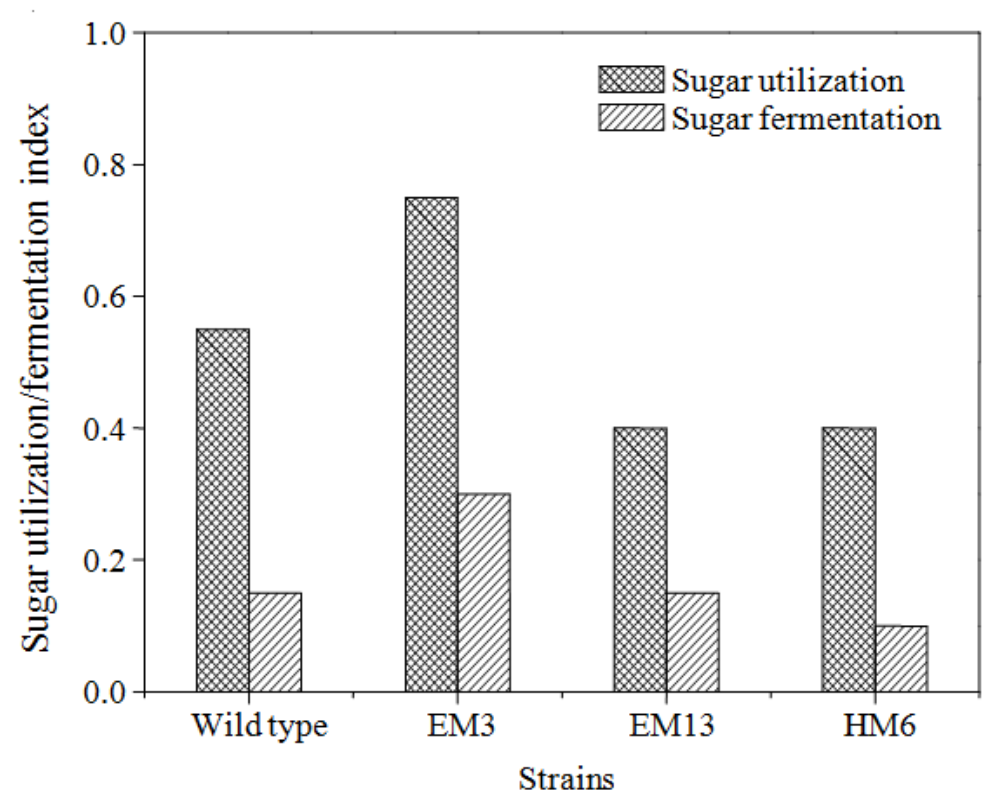

Fig. 5. Sugar fermentation and utilization pattern of the wild type strain and selected amoxycillin-resistant mutants (EM3, EM13, HM6) of H. xianhensis SUR308

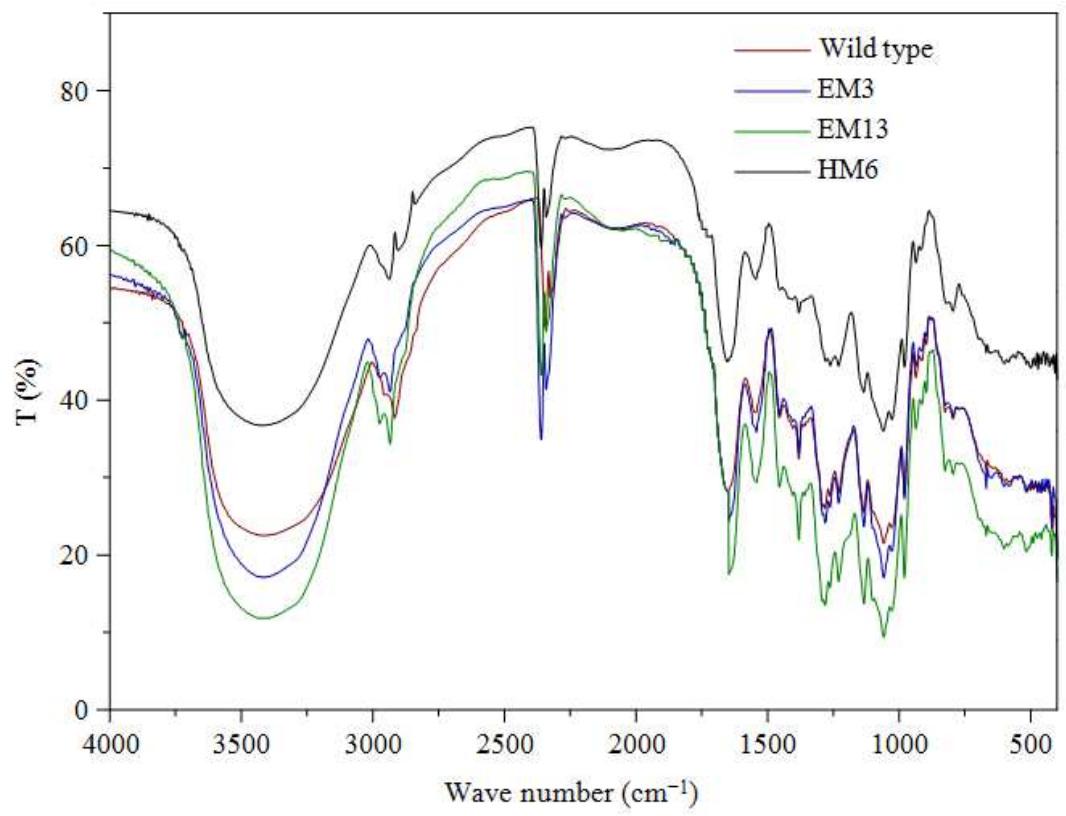

Fig. 6. FTIR analysis of EPS produced by the wild type strain and selected amoxycillin-resistant mutants (EM3, EM13, HM6) of $H$. xianhensis SUR308

Table 1. Screening of amoxycillin-resistant of mutants of H. xianhensis SUR308 for production of EPS

\begin{tabular}{lcccc}
\hline & & \multicolumn{2}{c}{ EPS production $\left(\mathrm{g} \mathrm{L}^{-1}\right)$} & \\
Mutagen used & No. of mutants & $-0.5-3.0$ & $3.1-6.0$ & 12 \\
\hline Hydroxylamine & 16 & 3 & - & - \\
Acridine orange & 1 & 1 & 25 & 2 \\
Ethyl methanesulfonate & 41 & 14 & 37 & 3 \\
Total & 58 & 18 & & \\
\hline
\end{tabular}


Table 2. Antibiotic susceptibility pattern of the wild type strain and amoxycillin-resistant mutants of H. xianhensis SUR308 H. xianhensis strains

\begin{tabular}{|c|c|c|c|c|}
\hline \multirow[b]{2}{*}{ Antibiotic } & \multirow[b]{2}{*}{ Wild type } & \multicolumn{3}{|c|}{ Amoxycillin-resistant mutants } \\
\hline & & EM3 & EM13 & HM6 \\
\hline Amoxycillin $^{30}$ & $\mathrm{~S}$ & $\mathrm{R}$ & $\mathrm{R}$ & $\mathrm{R}$ \\
\hline Kanamycin ${ }^{30}$ & $\mathrm{R}$ & $\mathrm{S}$ & $\mathrm{S}$ & $\mathrm{R}$ \\
\hline Methicillin $^{5}$ & $\mathrm{R}$ & $\mathrm{R}$ & $\mathrm{S}$ & $\mathrm{S}$ \\
\hline Neomycin ${ }^{30}$ & $\mathrm{R}$ & $\mathrm{R}$ & S & $\mathrm{R}$ \\
\hline Netillin $^{10}$ & $\mathrm{R}$ & $\mathrm{R}$ & $\mathrm{S}$ & $\mathrm{R}$ \\
\hline Streptomycin ${ }^{10}$ & $\mathrm{~S}$ & $\mathrm{~S}$ & $\mathrm{~S}$ & $\mathrm{R}$ \\
\hline ARI & 0.368 & 0.421 & 0.263 & 0.210 \\
\hline
\end{tabular}

Table 3. Heavy metal tolerance of the selected amoxycillin-resistant mutants and its comparison with wild type H. xianhensis SUR308 Tolerance level (mM)

\begin{tabular}{|c|c|c|c|c|}
\hline \multirow[b]{2}{*}{ Metal used } & \multirow[b]{2}{*}{ Wild type } & \multicolumn{3}{|c|}{ Amoxycillin-resistant mutants } \\
\hline & & EM3 & EM13 & HM6 \\
\hline Chromium & 4.0 & 0.5 & 0.5 & 0.5 \\
\hline Cobalt & 0.5 & 0.5 & 0.5 & 0.5 \\
\hline Nickel & 5.0 & 5.0 & 0.5 & 1.0 \\
\hline Cadmium & 0.5 & 0.2 & 0.2 & 0.5 \\
\hline Zinc & 0.5 & 0.1 & 0.2 & 0.2 \\
\hline Lead & 5.0 & 0.5 & 0.5 & 1.0 \\
\hline Copper & 5.0 & 5.0 & 5.0 & 0.5 \\
\hline Manganese & 10.0 & 10.0 & 10.0 & 10.0 \\
\hline Silver & 2.0 & 2.0 & 5.0 & 5.0 \\
\hline Mercury & 0.1 & 0.1 & 0.1 & 0.1 \\
\hline
\end{tabular}

Table 4. Elemental analysis of the EPS produced by amoxycillin-resistant mutants and the wild type strain of H. xianhensis SUR308

\begin{tabular}{|c|c|c|c|c|c|c|c|c|}
\hline \multirow[b]{3}{*}{ Element } & \multicolumn{4}{|c|}{ Weight (\%) } & \multicolumn{4}{|c|}{ Atomic (\%) } \\
\hline & \multirow[b]{2}{*}{ Wild type } & \multicolumn{3}{|c|}{ Amoxycillin-resistant mutants } & \multirow[b]{2}{*}{ Wild type } & \multicolumn{3}{|c|}{ Amoxycillin-resistant mutants } \\
\hline & & EM 3 & EM13 & HM6 & & EM3 & EM13 & HM6 \\
\hline $\mathrm{C}$ & 44.47 & 44.53 & 44.61 & 44.62 & 51.77 & 51.81 & 52.26 & 51.94 \\
\hline $\mathrm{O}$ & 54.54 & 54.57 & 54.21 & 54.31 & 47.67 & 47.66 & 47.11 & 47.46 \\
\hline $\mathrm{Na}$ & 0.61 & 0.71 & 0.98 & 0.68 & 0.37 & 0.43 & 0.50 & 0.42 \\
\hline
\end{tabular}

Further an asymmetrical stretching peak at $1647 \mathrm{~cm}^{-1}$ which corresponds to $\mathrm{C}=\mathrm{O}$ of aldehyde was found in each spectrum (Fig. 6). Elemental analysis of the EPS produced by the selected mutants showed similar weight percentages of carbon and oxygen atom to EPS produced by wild type $H$. xianhensis SUR308 (Table 4).

\section{Discussion}

Strain improvement, the essential component of process development in microbial biotechnology is achieved by introducing some specialized desirable characteristics in the strains as well as in the product (s) for increasing the productivity, reduction of costs and improvement of product (s). Such improved strains can be derived by genetic modification of the wild type strain and subsequent screening of the altered strains. Induction of mutation and selection of mutants to improve the productivity have been used extensively in industrial fermentation (Ghisalba et al., 1984).

So far the induction of mutation in halophilic organisms is concerned, viability and mutational frequency of Halobacterium cutirubrum in N-methyl $\mathrm{N}^{\prime}$-nitro-N-nitrosoguanidine was reported by Fitt et al. (1989), while Canovas et al. (1997) successfully isolated salt sensitive and auxotrophic mutant of Halomonas meridiana and $H$. elongata following hydroxylamine treatment. Likewise, Fernandez-Castillo et al. (1990; 1992) also worked on the mutagenesis of Haloferax mediterranei and several Halococcus spp. However, it was Llamas et al. (1999), who introduced chemical mutagenesis in an exopolysaccharide producing moderately halophilic bacterium, Halomonas 
eurihalina and were able to develop EPS deficient mutants for biochemical analysis of the process.

The present study was concerned in the isolation of EPS efficient mutants by random mutagenesis of the EPS producing moderately halophilic bacterium $H$. xianhensis SUR308. Survivality of $H$. xianhensis SUR308 against HA, AO and EMS as function of doses and time of exposure revealed (Fig. 1a-c) that EMS was the most toxic among the mutagens used, but most effective for induction of mutation (Table 1). This might be due to high permeability and penetration of EMS molecules into the growing cells of SUR308. Moreover, the wild type H. xianhensis SUR308 was comparatively more sensitive to hydroxylamine than that of the $H$. meridiana (Canovas et al., 1997). Acridine orange, the larger molecules were most probably unable to penetrate the cells and were least mutagenic.

Treatments showing 1-10\% survivality of cells were considered most suitable for mutagenesis and a total of 58 amoxycillin resistant mutant clones were obtained from such treated cells with a selection pressure of the antibiotic (Table 1). Development of such antibiotic resistance could be due to mutations in chromosomal loci (Davies, 1997) and the mutants are conventionally considered to have low levels of susceptibility (Martinez and Baquero, 2000) than the wild type. Likewise, mutagenesis of $H$. elongata and $H$. meridiana by HA has also been measured as a frequency of appearance of mutants resistant to streptomycin (Canovas et al., 1997).

Systematic evaluation of amoxycillin resistant mutants of $H$. xianhensis for the EPS production has lead to the selection of few mutants (EM3, EM13 and HM6) which showed significant increase in EPS production with reduction of incubation time (Fig. 2). In general, the EPS producing genes organized in an operon under a single regulatory system are involved in the biosynthesis of the repeat unit, polymerization, export and chain length determination (van Kranenburg et al., 1997; Huang and Schell, 1995). Mutagenesis in any one or more than one gene sequences might lead to constitutive expression of genes required for EPS production and thereby enhance the synthesis and accumulation of the EPS (Tang et al., 1991). Chemical mutagenesis in $H$. xianhensis remarkably increased the amount of EPS from 7.05 to $12.98 \mathrm{~g} \mathrm{~L}^{-1}$, an amount much higher $(4.9 \mathrm{~g}$ $\mathrm{L}^{-1}$ ) than that of the reported species of the genus Halomonas (Quesada et al., 1993; Arias et al., 2003; Mata et al., 2006). As against this, the EPS production of natural isolates of $H$. eurihalina ranged from 1.6-2.8 $\mathrm{g}$ $\mathrm{L}^{-1}$ (Bejar et al., 1998; Quesada et al., 1993). Similarly, marine bacteria belonging to the genera Alteromonas, Salipiger and Idiomarina produced very low amount of
EPS (1-1.6 $\left.\mathrm{g} \mathrm{L}^{-1}\right)$ and so far no attempt has been made to improve the EPS production efficiency of these strains by physical or chemical mutagens (Mata et al., 2008; Llamas et al., 2010).

Furthermore, the amoxycillin resistant phenotype of the selected mutants was also accompanied with changes in colony (Fig. 3) and cell morphology (Fig. 4) along with physio-biochemical features (Table 2 and Fig. 5) and heavy metal resistance profile (Table 3). The unusual elongated cell morphology of the mutant cell types might be due to impairment of cell division and separation during the process of growth. Moreover, such expansion and transformation to elongated cells could possibly be explained by the increased elasticity of the mutant cell types as against the wild type. In addition, salt sensitivity of the mutants of the isolate supported the observations of Canovas et al. (1997) with Halomonas spp. which could possibly arise due to alteration in the synthesis of compatible solutes responsible for haloadaptation in moderately halophilic bacteria. Further, FTIR and EDX analysis of EPS derived from mutant strains (Fig. 6 and Table 4) have apparently remained chemically unaltered.

\section{Conclusion}

Techniques for induction of mutation and strain selection based on morphological variation and antibiotic resistance have long been accepted as a routine practice to improve the yield of different industrially important biomolecules from bacterial strains. Improvement of EPS production by $H$. xianhensis SUR308 by chemical mutagenesis enhanced the production remarkably $\left(12.98 \mathrm{~g} \mathrm{~L}^{-1}\right)$. This increase will further reduce not only the cost of production but also the incubation period (3-4 days). The physico-chemical characters of the mutant derived EPS, however, have retained their identity with that of the parent strain. This study represents a successful method of chemical mutagenesis to obtain high yielding EPS efficient variants of $H$. xianhensis SUR308, a newly reported EPS producing moderately halophilic strain.

\section{Acknowledgement}

This study was financially supported by grants from University Grants Commission, India (Sanction No. F.14-2(SC)/2008 (SA-III), 31 March, 2009) under the scheme of Rajiv Gandhi National Fellowship.

\section{Author Contribution's}

Both the authors have equally contributed to this manuscript. 


\section{Ethics}

This article is original and contains unpublished material. The corresponding author confirms that all other authors have read and approved the manuscript and no ethical issues are involved.

\section{References}

Arias, S., A. del Moral, M.R. Ferrer, R. Tallon and E. Quesada et al., 2003. Mauran, an exopolysaccharide produced by the halophilic bacterium Halomonas maura, with a novel composition and interesting properties for biotechnology. Extremophiles, 7: 319-326. DOI: 10.1007/s00792-003-0325-8

Bejar, V., I. Llamas, C. Calvo and E. Quesada, 1998. Characterization of exopolysaccharides produced by 19 halophilic strains of the species Halomonas eurihalina. J. Biotechnol., 6: 135-141.

DOI: 10.1016/S0168-1656(98)00024-8

Biswas, J., S. Mandal and A.K. Paul, 2015. Production, partial purification and some bio-physicochemical properties of EPS produced by Halomonas xianhensis SUR308 isolated from a saltern environment. J. Biol. Active Products Nature, 5: 108-119.

DOI: $10.1080 / 22311866.2015 .1038852$

Bouchotroch, S., E. Quesada, A. Del Moral, I. Llamas and V. Bejar, 2001. Halomonas maura sp. nov., a novel moderately halophilic, exopolysaccharideproducing bacterium. Int. J. Syst. Evolut. Microbiol., 51: 1625-1632.

DOI: $10.1099 / 00207713-51-5-1625$

Canovas, D., C. Vargas, A. Ventosa and J.J. Nieto, 1997. Salt-sensitive and auxotrophic mutants of Halomonas elongata and H. meridian by use of hydroxylamine mutagenesis. Curr. Microbiol., 34: 85-90. DOI: $10.1007 / \mathrm{s} 002849900149$

Davies, J.E., 1997. Origins, acquisition and dissemination of antibiotic resistance determinants. Ciba Foundat. Symposium, 207: 15-27. PMID: 9189632

Dubois, M., K.A. Gilles, J.K. Hamilton, P.A. Robers and F. Smith, 1956. Colorimetric method for determination of sugars and related substances. Analytical Chem., 28: 350-356. DOI: 10.1021/ac60111a017

Fernandez-Castillo, R., C. Vargas, J.J. Nieto, A. Ventosa and F. Ruiz-Berraquero, 1992. Characterization of a plasmid from moderately halophilic eubacteria. J. General Microbiol., 138: 1133-1137. DOI: 10.1099/00221287-138-6-1133

Fernandez-Castillo, R., C. Vergas, J.J. Nieto, M. Megias and F. Ruiz-Berraquero, 1990. Efficient hydroxylamine mutagenesis of Haloferax mediterranei and other halophilic archaebacteria. Curr. Microbiol., 21: 83-89.

DOI: $10.1007 / \mathrm{BF} 02091824$
Fitt, P.S., N. Sharma and N. Barua, 1989. Studies of the effects of liquid holding on viability and mutation frequency in N-methyl-N'-nitro-N-nitrosoguanidinetreated halophiles. Curr. Microbiol., 18: 87-91. DOI: 10.1007/BF01570830

Gerhardt, P., R.G.E. Murray, W.A. Wood and N.R. Krieg, 1994. Methods for General and Molecular Bacteriology. 2nd Edn., American Society for Microbiology, Washington, D.C., ISBN-10: 1555810489, pp: 791.

Ghisalba, O., J.A.L. Auden, T. Schupp and J. Nuesch, 1984. The Rifamycins: Properties, Biosynthesis and Fermentation. In: Biotechnology of Industrial Antibiotics, Vandamme, E.J. (Ed.), M. Dekker, New York, ISBN-10: 0824770560, pp: 281-327.

Huang, J. and M.A. Schell, 1995. Molecular characterization of the EPS locus of Pseudomonas solanacearum and its transcriptional regulation at a single promoter. Molecular Microbiol., 16: 977-989. DOI: 10.1111/j.1365-2958.1995.tb02323.x

Iftikhar, T., M. Niaz, S.Q. Abbas, M.A. Zia and I. Ashraf et al., 2010. Mutation induced enhanced biosynthesis of lipases by Rhizopus oligosporus var. microspores. Pak. J. Botany, 42: 1235-1249.

Llamas, I., H. Amjres, J.A. Mata, E. Quesada and V. Bejar, 2012. The potential biotechnological applications of the exopolysaccharide produced by the halophilic bacterium Halomonas almeriensis. Molecules, 17: 7103-7120.

DOI: 10.3390molecules 17067103

Llamas, I., V. Bejar, M. Argandona, E. Quesada and A. del Moral, 1999. Chemical mutagenesis of Halomonas eurihalina and selection of exopolysaccharide-deficient variants. Biotechnol. Lett., 21: 367-370. DOI: 10.1023/A:1005483004140

Llamas, I., J.A. Mata, R. Tallon, P. Bressollier and M.C. Urdaci et al., 2010. Characterization of the exopolysaccharide produced by Salipiger mucosus A3, a halophilic species belonging to the Alphaproteobacteria, isolated on the Spanish Mediterranean seaboard. Marine Drugs, 8: 2240-2251. DOI: $10.3390 /$ Fmd 8082240

Margesin, R. and F. Schinner, 2001. Potential of halotolerant and halophilic microorganisms for biotechnology. Extremophiles, 5: 73-83. DOI: $10.1007 / \mathrm{s} 007920100184$

Martinez, J.L. and F. Baquero, 2000. Mutation frequencies and antibiotic resistance. Antimicrobial Agents Chemotherapy, 44: 1771-1777. DOI: 10.1128/AAC.44.7.1771-1777.2000

Mata, J.A., V. Bejar, P. Bressollier, R. Tallon and M.C. Urdaci et al., 2008. Characterization of exopolysaccharides produced by three moderately halophilic bacteria belonging to the family Alteromonadaceae. J. Applied Microbiol., 105: 521-528. DOI: 10.1111/j.1365-2672.2008.03789 
Mata, J.A., V. Bejar, I. Llamas, S. Arias and P. Bressollier et al., 2006. Exopolysaccharides produced by the recently described bacteria Halomonas ventosae and Halomonas anticariensis. Res. Microbiol., 157: 827-835. DOI: $10.1016 /$ j.2006.06.004

Nieto, J.J., R. Fernandez-Castillo, M. Megias and F. Ruiz-Berraquero, 1992. Ethyl methanesulfonate mutagenesis in extremely halophilic archaebacteria: Isolation of auxotrophic mutants of Haloferax mediterranei and Haloferax gibbonsii. Curr. Microbiol., 16: 21-25.

DOI: $10.1007 / \mathrm{BF} 01570098$

Quesada, E., V. Bejar and C. Calvo, 1993. Exopolysaccharide production by Volcaniella eurihalina. Experimentia, 49: 1037-104. DOI: 10.1007/BF01929910

Sreeju, S.N., M. Michael Babu, C. Mariappan and T. Selvamohan, 2011. Effect of physical and chemical mutagens on biopolm er producing strains and RAPD analysis of mutated strains. Archives Applied Sci. Res., 3: 233-246.

Sweet, D.M. and B.E.B. Moseley, 1976. The resistance of Micrococcus radiodurans to killing and mutation by agents which damage DNA. Mutat. Res., 34: 175-186. DOI: 10.1016/0027-55107(76)90122-6
Tang, J.L., Y.N. Liu, C.E. Barber, M.J. Dow and J.C. Wootton et al., 1991. Genetic and molecular analysis of a cluster of RPF genes involved in positive regulation of synthesis of extracellular enzymes and polysaccharide in Xanthomonas campestris pathovar campestris. Molecular General Genet., 226: 409-417.

DOI: $10.1007 / \mathrm{BF} 00260653$

van Kranenburg, R., J.D. Marugg, I.I. van Swam, N.J. Willem and W.M. de Vos, 1997. Molecular characterization of the plasmid-encoded gene cluster essential for exopolysaccharide biosynthesis in Lactococcus lactis. Molecular Microbiol., 24: 387-397.

DOI: 10.1046/j.1365-2958.1997.3521720.x

Ventosa, A., E. Quesada, F. Rodriguez-Valera, F. Ruiz-Berraquero and A. Ramos-Cormenzana, 1982. Numerical taxonomy of moderately halophilic Gram-negative rods. J. General Microbiol., 128:1959-1986.

DOI: $10.109900221287-128-99$ 